\title{
Crossing times: Temporal boundary-spanning practices in interorganizational projects
}

Stjerne, Iben Sandal; Söderlund, Jonas; Minbaeva, Dana

Published in:

International Journal of Project Management

Link to article, DOI:

10.1016/j.ijproman.2018.09.004

Publication date:

2019

Document Version

Peer reviewed version

Link back to DTU Orbit

Citation (APA):

Stjerne, I. S., Söderlund, J., \& Minbaeva, D. (2019). Crossing times: Temporal boundary-spanning practices in interorganizational projects. International Journal of Project Management, 37(2), 344-362.

https://doi.org/10.1016/.ijproman.2018.09.004

\section{General rights}

Copyright and moral rights for the publications made accessible in the public portal are retained by the authors and/or other copyright owners and it is a condition of accessing publications that users recognise and abide by the legal requirements associated with these rights.

- Users may download and print one copy of any publication from the public portal for the purpose of private study or research.

- You may not further distribute the material or use it for any profit-making activity or commercial gain

- You may freely distribute the URL identifying the publication in the public portal

If you believe that this document breaches copyright please contact us providing details, and we will remove access to the work immediately and investigate your claim. 


\title{
Crossing times: Temporal boundary-spanning practices in interorganizational projects
}

\author{
Iben Sandal Stjerne ${ }^{\mathrm{a}, \mathrm{c}, *}$, Jonas Söderlund ${ }^{\mathrm{b}}$, Dana Minbaeva ${ }^{\mathrm{a}}$ \\ ${ }^{\text {a }}$ Copenhagen Business School, Denmark \\ ${ }^{\mathrm{b}}$ BI Norway \& Linköping University, Sweden \\ ${ }^{\mathrm{c}}$ Technical University of Denmark (DTU), Denmark
}

Received 18 October 2017; received in revised form 14 September 2018; accepted 18 September 2018 Available online xxxx

\begin{abstract}
This paper introduces the notion of "temporal boundary spanning" and highlights the key role of project management in resolving temporal tensions among partners participating in interorganizational projects (IOPs). The present study, which is based on data from 93 IOPs undertaken within a major change program, relies on in-depth, semi-structured interviews, observations, and detailed analyses of written documents and procedures from those IOPs. Based on the data, we inductively develop a practice-based theory that identifies three main practices (framing, synchronizing, hyping) used to resolve the central temporal tensions observed in the studied IOPs. In that respect, the paper offers novel insights into the role and practice of project management in IOPs.
\end{abstract}

(C) 2018 Elsevier Ltd, APM and IPMA. All rights reserved.

\section{Introduction}

In the last few decades, the number and depth of collaborations across organizations (Ebers, 1997) aimed at realizing complex products, systems, and services has surged (Hobday, 2000). This development, which is evident in a range of industries and regions (Grabher, 2004; Jones and Lichtenstein, 2007; Maurer, 2010), has spurred a plethora of activities that are organized and coordinated through various kinds of interorganizational projects (IOPs). Such projects may be launched with the goal of developing new products and services, changing organizational routines, or building organizational capabilities across organizations.

Despite their popularity, IOPs entail fundamental challenges, especially as they require intense cooperation and coordination among actors from various sectors and institutional domains with disparate interests, professional identities, and organizational procedures (Dille and Söderlund, 2011; O'Mahony and Bechky, 2008). These actors are immersed in

\footnotetext{
* Corresponding author.

E-mail addresses: isst.si@cbs.dk (I.S. Stjerne),dm.si@cbs.dk (D. Minbaeva).
}

diverse permanent and temporal structures from which they draw when performing their daily work (Orlikowski and Yates, 2002). These structures intersect in IOPs, which often leads to goal conflicts, contractual disagreements, and a need for ongoing negotiation and coordination within the focal project in relation to dividing tasks and activities, and ensuring accurate communication among the actors involved. Prior research has highlighted the many and varied problems associated with efforts to establish cooperation and coordination arrangements that are acceptable to all parties involved in IOPs (see, e.g., Flyvbjerg, 2017; Manning, 2017).

As IOPs involve diverse sets of actors and organizations, cross-boundary interactions require the presence of common ground to facilitate knowledge integration; overcome differences with regard to cultures, languages, perspectives, and understandings (Bechky, 2003; Lenfle and Söderlund, 2018; Vijk et al., 2008); and solve numerous coordination-related issues (Mors, 2010). Furthermore, given their set deadlines (Lindkvist et al., 1998) and task-related interdependencies (Thompson, 1967), IOPs are likely to be characterized by conflicting pressures and priorities, as they involve actors and organizations with different temporal understandings and temporal regularities (Ancona and Waller, 2007; Dahlgren 
and Söderlund, 2001). Thus, the various degrees of temporal embeddedness in IOPs makes "temporal pacing" a core activity of managing such projects (Alioua and Simon, 2017). This activity includes setting clock-time demarcations, deadlines, milestones, and targets as well as matching project temporalities to the environment (Jones and Lichtenstein, 2007). In order to resolve these tensions, IOPs may utilize various mechanisms, including boundary spanners (Stock, 2006) and brokers (Reinecke and Ansari, 2015) who negotiate, balance, and demarcate boundaries around and within the focal project. These boundary spanners must also align and bridge the interorganizational boundaries among the organizations involved and enable the development of "ambitemporality" in interorganizational settings (Reinecke and Ansari, 2015).

The literature on IOPs has expanded in line with their growing societal and managerial importance (see Lundin et al., 2015; Manning, 2017). As a consequence, several scholars have called for more work on the theoretical foundations of IOPs as a particular organizational form (Sydow and Braun, 2017), and underscored the need to better address their governance, dynamics, and multi-level features. While the emphasis on social embeddedness is well developed theoretically and conceptually, the temporal embeddedness of IOPs has only recently gained scholarly prominence (Jones and Lichtenstein, 2007; Kenis et al., 2009). Despite the awareness of the importance of temporality and pacing problems in IOPs, which is evident in research highlighting their social and temporal embeddedness (Dahlgren and Söderlund, 2001; Jones and Lichtenstein, 2007), the temporal embeddedness of IOPs and the tensions arising in that regard remain conceptually underdeveloped (see Dille and Söderlund, 2011, and Reinecke and Ansari, 2015, for exceptions).

In this paper, we develop a practice-based theory that addresses the temporal tensions and boundary-spanning practices in IOPs. In so doing, we respond to calls for research into the unique features of IOPs as temporary and temporal organizational forms. By taking a practice-based approach (Feldman and Orlikowski, 2011; Nicolini, 2012), we address the micro-dynamics of everyday actions and interactions that produce organizational outcomes (Feldman and Orlikowski, 2011). More specifically, we are interested in what actually occurs in IOPs, especially how project actors identify temporal tensions and resolve them in their everyday work in order to achieve the purposes of IOPs (Selin, 2006). We center on practices as "embodied, materially mediated arrays of human activity centrally organized around shared practical understanding" (Schatzki et al., 2001: 11). These shared understandings are always informed by interwoven "timespaces" of various practitioners performing and (re)enacting practices. Such understandings are informed by various temporal norms and related temporal structures that orient practitioners' ongoing activities, such as weekly meeting, time schedules, activity plans, deadlines, and budget periods. However, changing these structures may involve significant tensions between project actors with disparate coercive timing norms (Dille and Söderlund, 2011), which has considerable consequences for project management (Dille et al., 2018).
This paper centers on the "temporal tensions" arising in IOPs in which the participating organizations subscribe to diverging temporalities and timing norms. In that respect, IOPs play a key role in both creating temporal tensions and ensuring that those tensions are overcome, thereby facilitating the achievement of the project's targets and ensuring that the project enjoys the support of its many stakeholders. We believe this approach conveys a novel perspective on the nature of IOPs and a novel understanding of the central management activities in this empirical setting. Theoretically, we build on and further develop the concept of boundary-spanning practices in IOPs (Casey, 2008; Stock, 2006; Werr et al., 2009). We focus on a specific kind of boundary spanning, which we refer to as temporal boundary-spanning practices. In this regard, we view boundary-spanning practices as central for project management in IOPs involving autonomous organizations with contrasting temporal understandings and temporal regularities (Zerubavel, 1981) that are often rooted in distinct institutional domains (Dille et al., 2018). However, contrary to mainstream research on boundary-spanning behaviors and practices, which focuses on the spatial dimensions of IOPs, we demonstrate that many boundary-spanning activities are directed toward identifying and sorting out the challenges associated with different temporalities among the involved partners. Thus, we focus on the following research questions: (1) What temporal tensions are involved in IOPs? and (2) What temporal boundaryspanning practices do project actors utilize to cope with those tensions?

Empirically, the paper zooms in on the "Tighten the Chain" (Stram Kceden in Danish; hereafter SK) program, a nationwide program initiated by the Confederation of Danish Industries in Denmark in 2015. The overarching goal of this major change program was to develop more effective and efficient collaboration among business-to-business clients and suppliers in order to optimize the supply chain and, ultimately, increase the competitiveness of Danish industry. The Confederation of Danish Industries identified 19 "anchor companies," which in turn assembled up to nine of their strategic suppliers and, together with those suppliers, identified and introduced new ways of collaborating. Our study is based on data from 93 IOPs undertaken within the SK program. It relies on data derived from in-depth, semi-structured interviews, observations, and analyses of written documents and procedures from these IOPs. Based on this data, we inductively identified three central temporal tensions that were resolved through three corresponding key temporal boundary-spanning practices.

The paper proceeds as follows. First, we discuss the theoretical background of our study, focusing on boundaries, boundary work in the intersections among temporary organizations, and the intermediating and interlinking role of boundary work among permanent organizations. Second, we outline the study's methodology and provide an overview of the SK program as the empirical context for our research. Thereafter, we detail the boundaries and tensions among the permanent organizations involved in the projects studied in our research. We then present in further depth the three main boundary-spanning practices that the project actors used to 
resolve the temporal tensions: framing, synchronizing, and hyping. In the discussion section, we address the implications of our findings for our understanding of boundary-spanning practices in IOPs and how the findings influence our understanding of how collaborating organizations seek to resolve temporal tensions on a more general level. Furthermore, our findings improve our understanding of why temporal tensions among collaborating organizations evolve and what managers can do to address those tensions. The paper ends with a presentation of a few ideas for future research.

\section{Theoretical background}

Jones and Lichtenstein (2007: 234) define a temporary IOP as "a nexus of activity that allows multiple organizations to collaborate to achieve their individual and collective goals. Hence, these projects can be understood as strategic ventures for change that require collaboration among the involved organizations. In that respect, one might argue that IOPs seek to push the interorganizational boundaries by aligning the essential processes and underlying temporal perceptions that organize the actions within the organization (Granqvist and Gustafsson, 2016). In this context, boundaries may be defined as borders or demarcation lines between categories (Hsu and Kocak, 2009; Zuckerman, 2016) that emerge as a result of subtle and complex actions and activities (White, 1992: 127). These boundaries create distance and distinctions between "us" and "them," and serve as a status demarcation that involves ongoing interpretive work (Gieryn, 1999: 5). Accordingly, boundary work (Gieryn, 1983) involves cooperation and coordination at the boundary (Kellogg et al., 2006), particularly in the absence of consensus (Star, 2010) owing to professional, disciplinary, or other divides (Bechky, 2003).

IOPs have been described as a new and unique kind of organizational form (Manning, 2017) that is characterized by strong temporal delimitations as well as expectations of cooperation beyond the focal project (Jones and Lichtenstein, 2007; Ligthart et al., 2016). The participating organizations develop "temporal commons" in the form of shared conceptualizations of "time and temporal values" (Bluedorn and Waller, 2006: 355), which establish strong temporal boundaries that shape actions based on specific timing norms (Granqvist and Gustafsson, 2016). Hence, temporal boundaries often delimit interactions (Klarner and Raisch, 2013; Souitaris and Maestro, 2010). They may also be a source for change, as they can be used strategically to facilitate large-scale transformations (Granqvist and Gustafsson, 2016), although this may give rise to temporal tensions and temporal misfits (Dille and Söderlund, 2011).

A central problem in IOPs is the need for collaboration among distinct, idiosyncratic organizations. These collaborating organizations might be embedded in different institutional environments and, therefore, subject to unique time-reckoning systems (Dille and Söderlund, 2011; Scott et al., 2011). Organizations might thus develop unique temporal regularities (Zerubavel, 1981) that may promote or impede collaboration in multiple ways across organizations. An organization's idiosyncratic time, which is nested in procedures, routines, and policies, might differ considerably from the idiosyncratic time to which a partnering organization responds. This creates a fundamental challenge for the management of IOPs, produces numerous cooperation and coordination problems (Dille et al., 2018), and may give rise to temporal tensions and asymmetries that require considerable management attention.

For these reasons, collaborating organizations need to either overcome or negotiate their temporal differences (see, e.g., Dille and Söderlund, 2013; Reinecke and Ansari, 2015). These issues seem particularly critical in the context of IOPs, which are characterized by timeframes for activity completion and by high degrees of task interdependencies, both of which call for mutual adjustments and synchronization among the actors involved. From a managerial viewpoint, there is a need to engage in activities that resolve temporal tensions among the organizations, negotiate time-related issues, and reduce the costs associated with "time collisions" (Reinecke and Ansari, 2015); consequently, a new form of boundary spanning transcending temporal dimensions of collaboration is called for. This assertion is in line with Kreiner et al.'s (2009) idea that boundary-spanning activities need to go beyond physical boundaries to cover other kinds of boundaries, including temporal ones. In their view, temporal boundary spanning is an important but neglected aspect of managing in interorganizational settings.

Despite the time-centered nature of projects and their explicit deadline orientation, extant research has predominantly focused on spatial dimensions when addressing boundaries and divergences (Kreiner et al., 2009). Recently, however, there have been several calls for a shift in focus toward temporal tensions and for examinations of the evolution of temporal boundary spanning in situ. In this paper, we define temporal tensions as the dilemmas and conflicts that emerge at the boundaries of opposing or competing temporal understandings, perceptions, and norms. To resolve these temporal tensions and ensure project progression, actors must be able to perform temporal boundary work, make use of their "temporal relational contexts of action" (Emirbayer and Mische, 1998: 970), and "construct, navigate, and capitalize on timing norms" (Granqvist and Gustafsson, 2016: 1010). Prior research has highlighted the need for scholarly scrutiny of the temporal tensions among partners in relation to views regarding when tasks need to be done, how quickly they need to be completed, and other "hidden rhythms" (Zerubavel, 1981) and "timing norms" (Dille and Söderlund, 2011) inherent in project collaboration.

The sociologist Zerubavel (1981) suggests ways in which the main rhythms and time-related problems might be researched, most notably by focusing on differences in the duration, frequency, timing, and pace of activities. As any practice is embedded in "timespace" (Schatzki, 2010), partners in an interorganizational context will have different views of these hidden rhythms. Indeed, organizations taking part in de novo interorganizational collaboration will have an opportunity to make these rhythms explicit to organizational members as they confront differing temporal practices (Orlikowski and 
Yates, 2002), some rhythms are inherently tacit and, therefore, difficult for the collaborating partners to articulate. Boundary spanning practices tend to span or "merge" the boundaries of disparate practices. That in turn create tensions because of not yet shared past-present-future orientations. Connections between past-present and future is what guide these activities; past memories and future expectations inform actors in conducting practices, as they are "coming toward that for the sake of which one acts (the future), coming or departing from that to or in the light of which one reacts (the past), and acting itself (the present)" (Schatzki, 2010, 170).

An IOP provides a new shared time, team, task and transition orientation (cf. Lundin and Söderholm, 1995), which constitute a starting point for triggering shared practices between different organizations that provide the basis for a new shared temporal organizing. Capturing such intricacies, calls for in-depth research that thoroughly addresses organizational processes and procedures, and that are able to detect their inherent rhythms and dynamic. In such research, the researcher plays a key and active role in detecting and addressing the idiosyncratic nature of temporal understandings and temporal practices (Orlikowski and Yates, 2002).

In addition to understanding the various temporal tensions involved in IOPs, it is essential to uncover how organizations work to overcome them. Reinecke and Ansari (2015) propose that organizations might develop a "temporal commons" and move toward "ambitemporality" to resolve differences in temporal requirements among the actors involved. The authors point out that empirical research must consider not only management as a mechanism for identifying temporal tensions but also management's role in negotiating differences among competing temporalities. As we discuss below, this is an important part of temporal boundary spanning in IOPs.

This paper aims to identify the temporal boundary-spanning practices that project actors utilize to resolve the temporal tensions associated with IOPs. In the following, we describe the empirical context that we used to identify temporal tensions and boundary-spanning practices in IOPs.

\section{Research setting and methods}

This paper draws on an in-depth, longitudinal case study of a unique transformation program involving a plethora of organizations from both the private and public sectors. The SK program represents an attempt to govern the Danish manufacturing industry and establish a common political vision aligned with "Industry 4.0." This ambitious program offered the potential for significant changes in the participating firms' supply chains, and it was intended to have an enduring impact on the interorganizational practices of the participating firms "by moving them closer together" (internal document). The goal was to improve productivity and reduce costs by, for example, optimizing interorganizational workflows, inventory management, and logistics. The SK program was designed to serve as a learning experience that would enable Danish manufacturing firms to continuously optimize their supply chains. Companies were expected to "start working with their suppliers in new ways" (Management Consultant, Consulting Firm).

The SK program, which was initiated in June 2015, involved 19 Danish manufacturing companies and their most strategic and important suppliers. In total, 126 companies participated in the SK program and 109 IOPs were initiated to realize its overarching and ambitious goals. In the program's pre-launch phase, the program owner from the Confederation of Danish Industry (DI) introduced the idea to a range Danish manufacturing companies of various sizes and from different locations. The SK manager early emphasized that "you need to invest in order to make money" and that "SK is an investment in learning how to save money without hard-core cost cutting" (DI Senior Consultant, field notes). This manager's primary role was to serve as a neutral party in interorganizational collaboration, communicating that "this [overall] project is not about price negotiations" but about creating win-win situations for all participating organizations.

There were five main requirements for participation in the SK program. First, the companies had to involve five to ten of their most strategically important Danish suppliers. Second, the participating companies had to assign two employees to a local project for at least two months. Third, the participating companies had to agree to follow a given timeframe for implementation and transition that was stipulated by the project owner. Fourth, the participants were required to utilize a predefined language and tools developed by the consultants involved in the program. Fifth, the participating companies were asked to present and communicate their results and the knowledge gained from the SK program to other companies, consultants, and researchers.

In the initiation phase, it was essential to identify a local "project owner" in each of the 19 host organizations and to ensure that the top management teams of each of participating organizations allocated sufficient resources to the projects. In addition, each company was asked to name boundary spanners, known as "supplier development agents" (SDAs), responsible for driving the SK projects. Each participating company identified between three and ten SDAs, who were responsible for driving the implementation of new work procedures and improvement measures. They subsequently identified the initiatives within their organizations that would be prioritized. After the initial meetings, each firm and its suppliers participated in a two-day workshop with the intention that "no one would leave the workshop before there was agreement on key initiatives to be implemented" (DI Consultant, field notes). The first day of the workshop was devoted to developing the understanding of the tools, mapping the collective supply chain flows, identifying initiatives for a leaner supply chain, and planning future initiatives. The second day was devoted to documenting the identified initiatives and ensuring ownership over them.

After the workshop, the SDAs took responsibility for implementing the initiatives in their respective host organizations. In this regard, the SDAs served as drivers of change, which required change-management skills, a thorough understanding of business and operations across departmental silos, 
as well as political and negotiation skills. In order to have a greater impact on Danish industry in general, all 19 lead companies presented their SK initiatives and preliminary results at various conferences (for an overview of the SK process, see the Appendix A).

In total, we collected data from 93 projects within the SK program. Our intention was to inductively explore the various tensions within these projects, and then to identify the measures and practices used to resolve those tensions. Data collection began in June 2016 and continued until February 2018 when the last of the participating companies officially ended their local SK projects. As mentioned, we relied on a variety of data sources, including interviews, written documents, and observations.

We conducted 51 in-depth, semi-structured interviews with key informants involved in the projects (see Appendix A). The interviews lasted between 45 and $146 \mathrm{~min}$, and they were conducted by the first author between October 2016 and February 2018. The interviews were conducted using a detailed interview guide that focused on the four main phases identified in the projects: 1) incentives to participate and prior supplier relations, 2) preparation and project start-up, 3) implementation of improvement efforts, and 4) discussion of collaboration and operations in the future. This ensured that the respondents could provide in-depth descriptions of their respective projects and engage in storytelling about relations before, during, and after the project. The questions were open-ended in order to provide the respondents with opportunities to tell their stories and give details about their perceptions of what occurred in the project.

The person responsible for the SK projects in each organization was asked to set up individual interviews with the most central participants in the focal project. In six cases, this resulted in group interviews with two to five informants per occasion. We are aware of the difficulty of revealing sensitive information in such settings. However, these group interviews allowed for more interactive and dynamic responses. Data on more sensitive matters were gathered in the individual interviews (see Appendix A).

Observations were conducted during different stages of the various projects. More specifically, the observations covered six days of initiation workshops, five days of postimplementation workshops, one program conference, one production meeting, and seven follow-up supply chain meetings. All observations were conducted in natural settings. The supply chain meetings delved into selected supply chains and provided more nuanced insights into the interorganizational aspects of the changes in collaboration and boundary work. We were invited to attend these meetings by the customers in the supply chain relationships, which served as a more powerful point of entry, as suppliers can find it difficult to speak openly on these matters. We ensured ethical responsibility by confirming that all participants knew why we were attending the meetings and the purpose of the data collection, and we stated that any anonymized quotes published in our study would first be provided to the relevant individuals for approval.
Our data analysis followed an "abductive" approach (Alvesson and Sköldberg, 2011), as it involved an iterative process of moving between the empirical data and the theoretical framework. This occurred while data collection was still underway, which helped us to further investigate emerging codes and themes. Initially, our main focus was on certain aspects of supplier-customer relations in the IOPs. However, after we had conducted 25 interviews, we became aware of the importance of various temporal concerns, as interviewees often emphasized this factor as critical for the project and for collaboration among the partners. Interviewees mentioned a number of temporal tensions, including the timing of implementation efforts. They also highlighted the importance of temporal concerns for long-term interorganizational relations and the importance of taking a long-term perspective on activities in the project. For these reasons, we added temporal tensions to our interview guide and investigated this issue further, remaining open to the possibility of more codes emerging.

When we analyzed patterns across the codes in the first stage of our analysis, the majority of the tensions appeared to be temporal. They emerged in the interorganizational setting because of temporal misfits between the customer and supplier organizations, or between the organizations and the local SK project. The obvious temporal tension, which was also the main incentive for more than half of the companies that participated in the SK program, was evident in discrepancies in understandings of time, which were experienced as deficits in planning and constant delays. During the interviews, it became apparent that incentives for utilizing the SK program were limited in projects characterized by a short time horizon, which further sharpened our focus on this tension. In addition, almost all project owners mentioned that it was hard to implement the changes while daily production continued. This was a significant obstacle to achieving the optimization envisioned by the SK program.

In seeking to refine this theme of temporal tensions, we moved between theory and data, seeking a way to conceptualize and seek out temporal tensions in our data. We analyzed the temporal tensions across the various projects in our study using the different project stages as an initial "processual order." In this process of moving back and forth, it seemed natural to attempt to understand how different project actors sought to resolve these temporal tensions. Our empirical data showed that each SK project had several predefined "supply development agents," whose primary role was to ensure that the project moved forward and that impediments were removed. This aspect forced us to carefully analyze how actors responded to temporal tensions and resolved them. To address these issues, we relied on recent research on temporal work, including Reinecke and Ansari's (2015) concept of "temporal brokerage," and Granqvist and Gustafsson's (2016) notion of "temporal institutional work." As we attempted to bridge the gap between our empirical data and extant theory through conceptual leaping (Klag and Langley, 2013), we conceptualized the boundary-spanning practices used to resolve the temporal tensions by elaborating on the concept 
Table 1

Coding of temporal tensions

Representative quotes and observations

"As we are working in a value network (simultaneously delivering to a building construction project), we have a different relationship with these companies. ... Sometimes they enter a project in the beginning and other times they enter very late. ... It is not a supply chain. ... We are competing in terms of collaboration partners 1000 times per day, so we are like children from different marriages. ... We all want to earn money and that is our common goal, but they do not want to make that money together. That is a huge challenge." (Project Manager, Construction Alpha)

"When you choose a supplier, it almost has to be one that you know you will still be working with in five years. There is no point in finding the perfect solution ... and then, in a year, say, 'You are too expensive, so I will not bother anymore.' They are our people but they are paid by (supplier name) and they know exactly what it takes ... how to do it and how we usually do things around here." (However, this did not appear to be possible with all of the suppliers invited to take part in the SK project.) (Global Procurement Manager, Food Delta)

"The customer (Energy Supplier) requested a more permanent staffing solution from their supplier responsible for temporary staffing. The staff members need to be experienced, highly qualified electricians. However, because of security issues, there are often hour-long interruptions at the workplace, which irritates the electricians and adds unnecessary expenses for the Energy Supplier. Nevertheless, this situation cannot be changed, as regulations pertaining to security issues must be followed. The Energy Supplier does not want to hire a permanent employee for these positions because of the cost, but the Energy Supplier continually tells the Staffing Supplier that it only wants the electricians it usually has." (workshop field notes)

"We can never choose from among prior partners if we need to put out an EU tender. We have specific criteria on which we need to base our selection and we cannot avoid them. ... We need to pick those that best meet the criteria. However, this is only for major projects. We would like someone with airport-specific experience and someone who is not overloaded with other projects. They would never say no to a job offer ... so we need to evaluate how busy they are." (Project Manager, Transport Beta)

"The hardest part is the delivery times ... because it takes time for a truck to drive from Denmark to Poland. Then you need to take a closer look at the machine room of the supplier-look into their processes. That is, of course, also the most difficult area to access. It was great to have a consultant involved in the SK process because we did not have to be the wise guys telling them how they should organize their production activities." (CEO, Transport Alpha)

"One thing we worked on was creating more time for improvements at the building site. It would be great if we could focus more on improving collaborations because there is a high cost in terms of time and resources for both of us when various tasks are still not done eighteen months after a project has ended. ... Of course, I can tell them, 'This is missing,' but nothing ever happens. In the end, our own operations need to fix it. ... There is only a carrot or a stick-the stick takes the form of day fines and the carrot is a bonus. However, neither of them work." (Project Manager, Transport Beta)

"It is about getting rid of the tension. We try to keep the tension from trickling down to the rest of the organization. ... If the supplier cannot find a single weekend in the next six months ... then I do not want anything to do with them. We need to find a solution or people will start to work against it." (IT Manager, Transport Alpha)

Food Gamma and one of its suppliers had a fallout because of different understandings of the "right" delivery time. The customer wanted a quicker delivery time and stated that most goods were delivered late. The supplier disagreed and looked for proof that the goods were delivered according to the agreement. (Workshop observation, field notes)

At the workshop, one of the car-accessory firm's suppliers highlighted the very quick delivery time on its products. This was questioned by the customer's CEO, who did not want to work with unrealistic numbers. (Workshop observation, field notes)

"It is better to be realistic about when you get your deliveries. ... Besides, no one says that a short delivery time is always the best." (CEO, Automotive)

"We have primarily been met with statements like 'We do not have time for this.' It is difficult to pull out the resources (to invest in the SK project). The hardest part has been maintaining focus (on the SK project) because this is still just a project. ... Everyday life is dangerous and stressful in an operational organization like ours. The need to continuously return to project implementation and ensure that everything is under control has been very challenging." (Procurement Manager, Service)

$\begin{array}{lll}\text { First-order code } & \text { Second-order code } & \begin{array}{l}\text { Aggregated } \\ \text { concept }\end{array} \\ \begin{array}{ll}\text { Short-term } \\ \text { collaboration }\end{array} & \begin{array}{l}\text { Temporary- } \\ \text { permanent tension }\end{array} & \begin{array}{l}\text { Time-horizon } \\ \text { tension }\end{array}\end{array}$

Lack of common

goals for the future

Longer-term

future

collaboration and

commitment

\section{Creating}

permanence in a

temporary

relationship

Forced

interruptions and

requests for prior

local experience

Interfering in

suppliers'

processes to

decrease lead

times

Negotiating

interorganizational

timeframes during

and after

interorganizational

projects

Mismatch in pace

that creates

internal tensions

\section{Serving}

organizational

self-interests and

perceptions of

pace

Fit and negotiation

of

interorganizational

pace

Maintaining focus
Temporary-

permanent tension

Time-horizon

tension

Temporary-

permanent tension

Time-horizon

tension

Temporary-

permanent tension

Time-horizon

tension

Interorganizational Pacing tension pace tension

Interorganizational Pacing tension pace tension

Interorganizational Pacing tension pace tension

Interorganizational Pacing tension pace tension

Interorganizational Pacing tension pace tension

Urgent routines Continuity tension and a vague future 


\begin{tabular}{|c|c|c|c|}
\hline Representative quotes and observations & First-order code & Second-order code & $\begin{array}{l}\text { Aggregated } \\
\text { concept }\end{array}$ \\
\hline $\begin{array}{l}\text { "We have a very busy daily life and that is true for everyone in the department. That is why we } \\
\text { have a tendency to continue 'driving on square wheels'-we have no time to stop and change to } \\
\text { round ones. That is how it is. Change initiatives really need to be motivating in the right way or } \\
\text { everyone thinks 'I am so busy right now that I cannot really make a change'." (Finance } \\
\text { Assistant, Food Delta) }\end{array}$ & $\begin{array}{l}\text { Efforts to change } \\
\text { direction }\end{array}$ & $\begin{array}{l}\text { Urgent routines } \\
\text { and a vague future }\end{array}$ & Continuity tension \\
\hline $\begin{array}{l}\text { "It is always difficult to say, 'Now we actually need to make these changes,' and to sit down and } \\
\text { meet. One week after another goes by and there is always something in the way, such that more } \\
\text { time goes by between each meeting. ... Eventually, everyday life takes over." (CEO, Montage) }\end{array}$ & $\begin{array}{l}\text { Unexpected issues } \\
\text { "stealing" time }\end{array}$ & $\begin{array}{l}\text { Urgent routines } \\
\text { and a vague future }\end{array}$ & Continuity tension \\
\hline $\begin{array}{l}\text { "There is a long way from thought to action. When we sit here, we come up with good ideas and } \\
\text { want to save the entire world. It is more difficult to get things started and get the process up and } \\
\text { running." (Controller, Food Gamma) }\end{array}$ & $\begin{array}{l}\text { Difficulties in } \\
\text { executing abstract } \\
\text { plans in everyday } \\
\text { work }\end{array}$ & $\begin{array}{l}\text { Urgent routines } \\
\text { and a vague future }\end{array}$ & Continuity tension \\
\hline
\end{tabular}

of "temporal boundary spanning." We further developed this concept by revisiting the data from all 93 projects and reexamining it with the intention of teasing out how project actors resolve temporal tensions.

Table 1 presents the codes derived from the data. We identified three temporal boundary-spanning practices used to overcome temporal tensions: framing, synchronizing, and hyping. These practices were used by the actors to resolve, negotiate, and capitalize on the temporal tensions among the organizations participating in the IOPs.

\section{Findings}

Our study of the SK program and its related projects identifies three tensions associated with time and temporality that were present in the studied IOPs. Here we are particularly interested in the nature of these temporal tensions, and in how they were addressed and managed by the project actors involved. More specifically, we focus on how project actors coped with these tensions and how they collectively negotiated solutions to resolve them. We believe our findings have several implications for the general understanding of IOPs as organizational forms, and for our understanding of the nature and role of management in these interorganizational settings. We also believe that similar tensions and the practices that the actors use to address them might be found in multi-partner projects resembling those in the SK program.

As discussed earlier, we engaged in a practice-based analysis to identify the mixture of practices used to cope with the contrasting temporalities among the actors involved in each project. In many ways, these tensions illustrate the underlying rationales for organizing a project like those in the SK program and the focus of management in such projects. One important rationale is that these projects both create and resolve tensions. If there were only a few, relatively modest tensions (e.g., economic, temporal, spatial), there would be little reason to organize a project in the first place. In such circumstances, coordination and cooperation could instead be target through low-intensity coordination mechanisms (Oliveira and Lumineau, 2017; Van de Ven et al., 1976). However, tensions and solutions are central to these kinds of projects, and the tensions and solutions form a blend that changes throughout the course of the project. Thus, in addition to understanding the nature of the tensions and how they are resolved, we are also interested in how tensions emerge over the course of an IOP. In that sense, although we do not provide a complete longitudinal account of the various projects in the SK program and their temporalities, we are interested in offering a dynamic understanding of the tensions and temporalities involved in IOPs.

\subsection{Temporal tensions}

We address three main temporal tensions that characterize interorganizational collaboration in the SK projects covered in our research: time-horizon tensions, pacing tensions, and continuity tensions. In this context, we refer to "tensions" as instances and incidents in which actors representing various organizations have different views and understandings of time and temporality, which in turn negatively affect the atmosphere of collaboration. In the subsequent section, we address the key temporal boundaryspanning practices used to cope with these temporal tensions.

\subsubsection{Tension I: time-horizon tensions}

The first tension is associated with the conflict between shortterm and long-term priorities and investments, and it concerns the projected time horizons of the interorganizational collaboration. A central aim of the SK program was to improve collaboration by creating a better understanding of suppliers' and customers' different time horizons. Actors involved in the program repeatedly pointed to the importance of ensuring a clear understanding of each other's situation and of the various time horizons involved. This time-horizon tension was clearly evident, as the SK program was designed as an investment in improving future collaboration among firms in the supply chain. All parties were required to take a stance on whether they believed that the collaboration would cover the long or short term before venturing into an SK project together. One such consideration was highlighted by a representative of a client firm ${ }^{1}$ :

\footnotetext{
${ }^{1}$ The quotes are from our interviews unless otherwise indicated.
} 
When we choose a supplier, it needs to be a company that we believe we can work with for at least for five years. It is useless to sit down and find a standard solution by inserting a comma here and there in order to get our goods faster if, in a year, we will say "You are too expensive, so I will no longer buy the goods from your company." That does not work from our point of view. (Strategic Sourcing Manager, Food Delta).

In interorganizational relationships based on longer-term horizons, tensions arose from a strong lock-in in the form of projections for the future. Although the suppliers were indispensable strategic partners for the focal companies, they did not act as if they shared a mutual interest in investing in improving the collaboration by addressing daily inefficiencies or unsatisfying deliveries. This triggered tensions between past experiences of unmet expectations and the view of an optimistic and better future, which created a sense of "temporal leap" between past experience and projections for the future. However, these projections were not always realistic because of past experiences and the need to continue the collaboration. This was described as a "forced marriage" in which the SK program largely functioned as a counselor that could help reduce the past-future discrepancies.

Frequently, interorganizational collaborations existed owing to financial investments, legal contracts, and a lack of alternative suppliers. Most often, they reflected a need for suppliers with company-specific knowledge:

The truck operators are very important to our daily operations. ... I have decided to allocate all transportation to one supplier because then I get another service-the same truck operators drive down here every day. They are more [name of the client company] than [name of the supplier company]. They are "our people" even though their salaries are paid by [name of the supplier company]. They know exactly what to do and how we do things around here. (Global Procurement Manager, Food Delta).

In relationships based on shorter-term horizons, tensions arose from a lack of clarity concerning the collaboration's horizon. The goal of the SK program was to address long-term interorganizational relations. Vague demarcations of the time horizon made it difficult to create a "shared projection for the future" or "common ground" in the local IOPs. Both parties had an incentive to reduce costs, but it seemed unrealistic to align interorganizational activities when the projections for the collaboration were unstable. This resulted in a sense of discrepancy between investing enough in a collaboration to maintain it and insecurities about whether the investment would pay off in the long run. Different contextual preconditions were an important reason for these delimited time horizons. Some organizations participating in the SK projects were relatively young and the interorganizational relations in these cases were still under development. Others operated in uncertain markets or in volatile, project-based industries, such as construction, with more clear-cut temporal delimitations. Others were public companies that were obliged to adhere to certain routines and procedures, such as procurement regulations, which frequently influenced the quality of interorganizational relations and created time-limited relations lacking a common long-term vision. In the most extreme case, which was in the projectbased construction industry, the lack of projections regarding the future created fundamental time-horizon tensions and difficulties in establishing close, long-term partnerships. This uncertainty caused suppliers to increase prices, as there was not enough time, trust, or incentive to discuss long-term sustainable solutions.

We compete in terms of our collaborators a million times per day, so we are more like children of composite families. ... The value chain is fragmented and some information gets lost, and there is a conflict-oriented culture. There is more money in being good at destructively triggering conflicts than in proactively handling them well. We all want to make money. ... Everyone wants the same thing, but they don't want to do it together. (Project Manager, Construction Alpha).

In sum, this tension revolves around time horizons and is, to a great extent, future oriented, as it arises from either too many or too few projections regarding the future of the interorganizational collaboration. As seen in our empirical account, overly long or short temporal frames create tensions that negatively affect collaboration in IOPs, as the incentives to invest in optimization depend on the time horizon. Views on what constitutes long or short term also vary considerably among the actors involved, spanning from several decades to only a few years or even a few months. As we discuss later, resolving this temporal tension requires considerable effort aimed at framing time horizons.

\subsubsection{Tension II: pacing tensions}

The second tension, which surfaced clearly during workshops and meetings held in conjunction with the SK projects, was a result of efforts to resolve the daily tensions that emerged in the collaborations with regard to disparate timing norms. In particular, tensions pertaining to the pace of interaction arose. In this regard, the lead consultant in the SK program indicated that " $50 \%$ have reported that the deficit in planning is challenging" (Consultant). These discrepancies caused frustrations and difficulties in interorganizational collaboration, as they led to delays in the manufacturing process, and impaired manufacturing and organizational productivity.

One common tension that caused frustration and dissatisfaction in relationships with suppliers related to different perceptions of what it meant to deliver on time. This was associated with internal procedures, order-handling processes, and processes for replying to collaborating partners:

The suppliers need a lot time to get things done. When we press for our goods, saying "I have a customer waiting," we are told "You will get it the day after tomorrow." Then you hear from other people in the organization that they have similar products but under other brands, which they have already received. However, they do not need them until 
tomorrow. Then you become a little frustrated! (Coordinator, Food Alpha).

Self-interest also played a key role in these perceptions. Customers requested a high degree of flexibility and short delivery times, which set a number of pace requirements for suppliers. At the same time, suppliers favored flexibility in order to fit production to their own pace and systems. As one procurement manager stated when describing suppliers delivering the required products later than agreed:

I really don't care how you get them here or at what time. They just need to be ready when we meet in the morning so that I don't have to wait for them. (Global Procurement Manager, Food Delta).

Different timing norms permeated the entire flow of production. When this became apparent, it was a natural cause of considering a legitimate pathing or "diverse," as the interviewees often described it. An example of such conflicting timing norms was found between two suppliers that had faced several challenges in terms of batch sizes being too large and often delayed. The SK project was set up to optimize the interorganizational flow, but the parties eventually determined that doing so was impossible:

Given the supplier's setup, we found that we didn't actually fit together. When we visited them, we understood that their KPIs were the number of cartons they produced per day and machine downtime. How does that fit with our need for small and flexible production series? They offered short delivery times but the amount produced was the same regardless of our needs. They only made large numbers and we do not use that many per year. If they were to give us the setup price plus the price per unit, then we could find the price for a smaller amount, but they didn't want to provide us with that amount because it conflicted with their minute count. (Procurement Manager, Interior Design Alpha).

The SK program's main objective was to create "win-win situations" in which both parties in a relationship could adjust their paces in order to ensure punctuality. Changes in pace were central to the SK program's overall aim of better aligning customers and suppliers with regards to lead times and timing. This idea relied on lean principles in which the incentive was to create a lean production flow based on an appropriate interorganizational delivery time (i.e., lead time). The main assumption was that shorter lead times were better, as longer lead times implied more uncertainty, larger stocks, and more waste for customers. However, longer lead times were of little importance and, in some instances even implied more flexibility for the suppliers.

Lead time is actually the reacquisition time for a specific product. The longer the lead time, the more insecurity it implies because you cannot really plan that far ahead. Therefore, let us squeeze it so that it matches with short-term operations. Suppliers do not always have an ear for this idea. (Procurement Manager, High Tech).
This desire to develop a mutual timing norm in the interorganizational collaboration and, thereby, reduce costs was highly motivational. The project workshops relied on "value-stream mapping," which used visualizations to sketch out an overview of the production flow with the intention of illuminating inefficiencies. This provided information on the overall pace of the production flow as well as ways to avoid delays.

However, it was still difficult to agree on the pace experienced in the past, which had been perceived differently by different actors, who at times became visibly frustrated in this regard during meetings. For instance, in one meeting, disagreements over the lead time in the past resulted in a major conflict between the supplier and client. The supplier claimed that rush orders took four to five days, while a normal delivery took two weeks. The customer challenged this, stating "We have never received a delivery in five days. In the best case, it takes ten days." The supplier's manager adopted a defensive attitude and started to look through mail correspondence to prove that he was right. The supplier found that $81 \%$ of all deliveries arrived in 9 or 10 days, and that $94 \%$ of orders were delivered in 12-15 days. The supplier and customer disagreed about whether these numbers were satisfactory because of changes in the customer's needs. The consultants tried to resolve the conflict by asking more open-ended questions and reminding participants of the vision of the SK program, which was to enhance productivity and interorganizational collaboration.

In sum, this tension revolves around disparate timing norms in terms of when and how quickly things should be done. It is also a matter of conflicting timing norms and goals among suppliers and clients, which affect negotiations regarding the pace and the definition of on-time delivery. Some organizations had strategies of being flexible and fast, but for a high price, while others were cost leaders in the production of standard goods. These strategies attracted certain actors and enforced certain timing norms. As companies collaborated with various clients, they often differed in their views on timing. This led to tensions, which were further escalated by the power relations between buyers and suppliers that hindered an "honest and open dialogue" aimed at finding mutually sustainable lead times. The resolution of this tension required addressing the power relations and aligning timing norms.

\subsubsection{Tension III: continuity tensions}

The third tension played out between daily operations and the desire for better collaboration in the future, which added tasks aimed at changing the daily operations. This tension was primarily experienced as an internal conflict, although it resided in the challenge of not being able to continue the daily operations within an organization while simultaneously changing those operations to fit the objectives of the SK program.

The focus was on transforming the past routines to the new SK mindset, which resulted in temporal perspectives competing for attention. The various SK initiatives were often perceived as side projects that were decoupled from the organization's daily operations. This tended to demotivate the people involved in 
the projects, who found that daily operations or new projects often received first priority. In one case, a highly motivated product manager discovered that what was viewed as truly valuable was getting new products onto shelves rather than making minor adjustments to workflows. He highlighted this discovery in an interview, and explained that the structured and intensive ways of working together during the workshop were difficult to maintain in an everyday setting due to the many operational issues that required attention. He also explained that he was highly motivated by making concrete deliveries to his clients and by seeing new products appear on shelves. Hence, in an organization's everyday work, the quick, short-term results competed with the longer-term rewards of optimizing for a potentially better future.

In many cases, this temporal tension seemed to be rooted in a similar production logic. The SK project introduced new tasks that would enable a transition toward a better, more efficient future with a promise of returns on investments. Despite these promises, the additional tasks took time away from the core task of delivering current orders:

The buyer of a product does not care that we are participating in the SK program. If we tell a customer that we are optimizing our supply chain, that customer will still want the goods on time. (Procurement Manager, High Tech).

The promise of a better return on investment was perceived as less reliable than the returns indicated by past experience. The value-stream mapping served to identify optimization potential and associated possible future savings. Although these identified future savings motivated both parties to optimize the supply chain, they were often perceived as vague and, to some extent, unrealistic, as they were only potential savings. As one procurement manager stated, "We are a grocery-driven company and we need something concrete before it counts" (Food Gamma). These savings were sometimes referred to disparagingly as "consultant money" and "funny money" because they were merely projections. Moreover, they were often estimated by consultants, who had an interest in exaggerating the likely total savings. At the same time, daily operations continued to be affected by urgent matters, making it difficult to implement the SK projects:

One of the biggest challenges is to keep focusing on assigning the resources necessary for the optimization. Our first priority will always be whether there is "water in the pipes." We would be upset with our suppliers if they did not deliver because they were taking part in the SK program. (Procurement Manager, Energy).

In sum, this tension emerged from a sense that tasks from the past and the future were competing for attention. It primarily resided in an orientation toward the past. Practices known to work and to give rise to profits in the past were maintained in order to avoid putting all emphasis on untested projections. In other words, the practices that were already known to work competed for attention, time, and resources with the new practices that promised even greater returns on investments in the future. The maintenance of the past practices was perceived as critical and important. Resolution of this tension required widely publicizing the successes and benefits of the new practices.

\subsection{Temporal boundary-spanning practices}

To resolve these temporal tensions, the actors relied on different temporal boundary-spanning practices. Our concept of "temporal boundary-spanning practices" refers to the various bundles of activities and everyday occurrences in which actors engage to address temporal tensions. We find three primary categories of temporal boundary-spanning practices: framing, synchronizing, and hyping (see Table 3), which are discussed in detail below.

\subsubsection{Practice I: framing}

The temporal boundary-spanning practice we refer to as framing was a response to the time-horizon tensions that were observed when project actors were engaged in either short-term or long-term collaborations. The practice of framing is primarily future oriented, and involves the use of various measures that extend or shrink the time horizon of the interorganizational collaboration. It is a way to motivate the other organization to set a new potential horizon that would make it mutually beneficial to invest time and money in the IOP. Clients often make use of future time horizons through an incentive scheme, which seeks to motivate suppliers to act in ways that are beneficial to the interorganizational relationship. This temporal boundary-spanning practice is exercised through small statements or hints that serve to reject, question, or ensure future collaboration. As such, this practice is used to increase or decrease the time-horizon tension in order to motivate additional resource investments, knowledge sharing, and relational stability or, more generally, to push for a better, more competitive product.

Time horizons are extended in order to increase trust, knowledge sharing, and collaborative stability. This is accomplished by appraising suppliers in different ways, perhaps by indicating the strategic importance of a focal supplier or by highlighting the potential for mutual business growth. A clear example of this was observed in an SK project workshop in which a small customer felt a need to motivate suppliers to invest in future collaboration. The customer, who was a supplier to the car-manufacturing industry, introduced the workshop by pointing to a common need and the opportunity to grow together:

We have had some challenges with communication in the past because we did not know each other's processes and this caused some frustration. We are expecting growth of DKK 80 million in revenue - an average growth rate of $30 \%$ per year-and we need to build a foundation for handling this growth. Collaboration is essential in this regard (and)... when we look ahead, we all need to focus on our common customers - the automotive industry. We know that you 
need to earn money and you know that we need to make money, and we are dependent on each other.

(CEO, Automotive, field notes)

The intention was to create a zone of comfort in which the suppliers and buyers felt free to share sensitive information, including details about internal production difficulties. The various SK projects provided a framework based on long-term relations and, hence, served to align the boundary-spanning practices with the entire SK program.

The strategy of shrinking time horizons was used to increase insecurity and, thereby, motivate suppliers to make an extra effort. This strategy enhanced the customer's bargaining power. The risk of losing a customer motivated suppliers to invest sufficient resources in the SK project. Customers often indirectly and directly challenged expectations of continued collaboration using their power to define the collaboration's time horizon, thereby keeping suppliers on their toes and continuously striving for improvements. However, doing so did not require them to directly criticize the relationship. This supported good spirits and communication, while suppliers were made aware that they needed to meet expectations. This strategy was evident in comments made by customers to remind suppliers of potential competitors. Some customers even invited competing suppliers to participate in the SK project and solve problems on a daily basis:

We invited a new supplier. Before, $x x x$ had the entire business, but now it is an $80 / 20$ split. ... They are competitors ... but there is room for both of them in our factory. There are plenty of conflicts, but we solve them in a different way. ... Now we invite them to the same table [to find solutions] and we tell them the same story so that no one gets more information. As such, no one has a competitive advantage in this regard. (Strategic Sourcing Manager, Food Delta)

At other times, the temporal boundaries were used to add pressure while negotiating the conditions for the interorganizational relationship. For example, upcoming bidding rounds or rivals were sometimes mentioned (SK workshop observations), which activated temporal demarcations that questioned the future of the relationship. This boundary-spanning practice was particularly evident in meetings held when the temporal tension was growing, such as those that occurred near the end of a contract that needed to be renegotiated. In the case mentioned above, for example, the general agreement between the buyer and supplier was about to expire. That IOP was composed of the customer and two suppliers, both of which were collaboration partners and potential competitors. In the quarterly SK project meetings, the discussion focused on the opportunity to start optimizing the workflow in order to improve the lead time and enhance product quality. After a few meetings on the optimization process in which one supplier had been pushing the other, the customer stated: "The best part is that the tender starts in a week, so we will see what happens." This indicated a desire for a better deal while avoiding an overcommitment to organizational change on the customer side. At the same time, the supplier was pushed to work harder to win the bid.

In the construction industry, which offered the most extreme cases of IOPs with delimited time horizons, the entire SK vocabulary had to be reinterpreted. In this industry, people tended to perceive each other as equal and mutually dependent partners, and companies often worked simultaneously on the same project, with some becoming involved earlier than others. The SK project used the term "supplier relation," which was perceived as indicating a traditional supply chain and a sequential temporal logic. However, in the construction industry, suppliers and customers often simultaneously collaborate in the same setting, making it difficult to apply a vocabulary that builds on the traditional framework. Therefore, one of the companies participating in the SK program changed the term to "partnerships" and created a framework that did not focus on the alignment of workflows between two companies. Instead, that framework covered a group of seven large companies collaborating in construction. These companies identified three industry challenges that they intended to solve together. In other words, the traditional understanding of a strategic supply relationship needed to be adjusted. In a group interview with SK project actors from a construction firm, one project manager discussed this issue:

An A3 [a tool offered by the consultants in SK program] is lean and tight. However, on the operational level, we cannot solve problems using this tool because each project is different. That is why it is more about strategic alignment of the projects. (Project Manager, Construction Alpha)

\subsubsection{Practice II: synchronizing}

The second practice, which we refer to as synchronizing, was a response to the tensions associated with pacing, which derive from the fact that organizations have their own timing norms and that collaboration in an IOP requires organizations to get in sync and find a common pace. The synchronizing practice was primarily focused on the present and required extensive negotiations based on defining the right flow of goods in the supplier-buyer relation. Past experiences from the interorganizational relationship were (re)interpreted due to differences in what was perceived to be the best pace for delivery and production, which often emerged in the IOP when the supplier and buyer negotiated the lead time for the production flow. The tensions related to pacing were resolved by renegotiating the optimal pace and the meaning of punctuality. To succeed in this regard, the customer needed to downplay its power and adopt a humbler position, so that the supplier felt that it was an equal partner. Instead of pointing fingers and demanding that certain tasks be completed faster, it was essential to optimize the supplier-buyer production process so that both parties adjusted their work practices and were able to identify the optimal pace for their internal and interorganizational contexts. If this was not possible, then the interorganizational collaboration was reconsidered or redesigned. 
In one SK project, lead-time issues were in focus during the workshop. Expectations regarding future collaboration centered around optimizing activities associated with just-in-time deliveries but not on an explicit objective of minimizing lead times. At the workshop, participants determined that there was quite a bit of wasted time. When the supplier stated a lead time based on its past experience, the customer framed this issue in a subtle manner, with the CEO stating: "Sometimes, we do actually wait for you. ... That lead time sounds impressive, but I do not think you ever actually achieved it." The supplier replied, "Well, yes, we did and we actually did even better." The customer manager continued, stating "Great! It can be done, but doing so is not optimal for you, is it?". This led to a broader discussion of whether quicker delivery times were actually better. In an interview after the workshop, the customer manager explained that: "It is better to know when you will get your deliveries. By the way, no one says that a short delivery time is always the best" (CEO, Automotive). This debate focused on the future instead of the past and it was constructive, as it questioned the assumption that shorter lead times are always better. This resolved the tension related to past experience by projecting ideals that were decoupled from that experience, and created an option to negotiate a shared temporal pace that would be optimal for the supplier and, hence, lead to a more stable production flow for the customer. The customer, in turn, would gain more predictability, which was better than pressing for lower lead times accompanied by delays and additional costs.

Such negotiations required the participation of people with sufficient insights and decision-making mandates, and no selfinterest in sticking to the status quo. They were delicate situations in which both parties needed to compromise based on concrete information. Such information was typically not provided by the sales manager, whose primary interest was to retain sensitive information and frame the supplier as positively as possible in order to increase sales. This was highlighted in a follow-up workshop with three customer companies:

You need to get behind the key account managers because they have a completely different agenda. The projects in the SK program that fail are those in which the suppliers shut us off through the sales manager and we never get behind the scenes. (Project Member, Food Gamma, field note)

Such insights can be supported by getting an insider into the firm, who can share knowledge on timing preferences and related issues. This point was mentioned in a follow-up workshop:

It helps if there are people who have worked for your company in the supplier firm or vice versa. It makes it easier to discuss whether we are actually booking at the right time.

... We had someone down there every Friday to discuss possibilities for optimization. (Procurement Manager, Food Gamma, field notes).

\subsubsection{Practice III: hyping}

The third practice, which we refer to as hyping, was a response to the continuity tensions associated with initiating a change while continuing daily operations. Hyping is primarily past oriented. It involves staging the project in terms of different past practices in a way that highlights and celebrates the need for change in order to bring people on board and to transform the organizational routines without negatively affecting daily production.

By tapping into the "pain points" of past collaborations and the need for continuous improvements in order to stay competitive in the industry, the SDAs created a "burning platform" for investing time and resources in projects at different organizational levels. Hyping at all levels was essential for resolving the continuity tension. As stated by one of the larger clients participating in the SK program, the procurement manager sold the SK program to the top management team by stating that the prior bargaining strategy was no longer sustainable or profitable for the organization because prices had already been pushed to the pain threshold. In fact, some suppliers had already been forced to refuse orders, as accepting them would result in deficits or bankruptcy:

For the past eight years, we have been running strategic purchasing using benchmarking and quantity pooling. ... However, we have harvested the same field a few too many times. When you do that, every company makes less profit every time. ... Now we are starting a new phase in which we enter into a partnership with our supplier in order to create more value and split the profit equally. (Procurement Manager, Service).

In order to resolve the continuity tension, each project needed a mandate from top management and from the employees who were making the changes. Top management's prioritization of the project was essential for ensuring that extra resources were allocated to daily operations to allow for the implementation of the initiatives. At the operational level, the challenges of changing routines while continuing production needed to be addressed to maintain the project's focus and pace. However, top management often only halfheartedly bought into the project, resulting in failure and a lack of resources for implementation.

Whether you enter a company with a political intent or one that is merely business oriented makes a difference. You start the conversation in very different places. ... It is important to be aware of what creates value for you. (DI Project Manager).

Generally, projects that were prioritized built on the firm's past projects and initiatives. Therefore, the top management team had already started the journey.

At the operational level, boundary spanners hyped the results of the SK projects to motivate employees to implement the changes that those projects required. Notably, employees who invested in the project needed to be rewarded. As one project owner suggested:

You need to make sure that the rewards from the SK initiative rain down, so that the people who make the effort 
get the benefits.

\section{(Procurement Manager, Food Alpha)}

Several employees who had not been involved in the SK program from the beginning needed to be initiated into the project, which required hyping the potential to remove daily frustrations and meaningless tasks from their work, and creating ownership of the initiatives. These small improvements needed to be celebrated. As explained by an employee involved in implementation:

It has been calm and quiet-mostly desk work. In the past, there was an awful lot of rushing up and down the ramp to get the trucks loaded with an endless amount of goods.

(Shop Floor Manager, Food Delta)

Furthermore, hyping implied staging the positive results from the SK project to show the success of the project and create more fans. This required temporal demarcations of changes to motivate employees to be involved. For example, one purchase manager carried out a small ceremony in the area from which stock goods that used to make a mess had been removed as a result of the SK initiatives. This was a matter of highlighting the small successes, and of assuring people that the SK project had realizable savings and that the payoff was satisfactory:

Actually, we worked on improving our internal processes, but I really believe that the key is to present some concrete results. We also worked on the "soft" parts of the processes, but hard results are just as important. (Process Excellence Director, Transport Beta).

This was a way of reminding people of the frustrations that had been removed because of the SK program. Another method of hyping a project was by inserting regular temporal markers into daily routines to ensure that the project had a persistent impact. In other words, the project practitioners sought to interrupt the past to ensure a focus on a new future. When participants were invited to a meeting, they felt a need to reengage and report their successes. In this sense, meetings recommitted actors to engaging in activities to which they had already committed. Meetings can be understood as temporal markers of expected actions. In several of the interorganizational settings, the SDAs held optimization meetings every quarter. These meetings were intended to ensure that initiatives kept moving forward and provided an opportunity to initiate new optimization processes. In these meetings, past orientations were highlighted and utilized to hype the need for the SK project.

\section{Discussion}

This paper addressed IOPs as a particular organizational form. We focused specifically on the temporality of this organizational form, and how project actors relate to time and timing. This enabled us to view IOPs as a time-oriented organizational approach that both reduces and activates tensions in interorganizational relations. As noted in our findings, three primary tensions were considered critical in the projects that were part of the SK program, and these tensions were identified as the main challenges for establishing cooperation and coordination in the projects covered in our empirical study. We referred to these tensions as "temporal tensions," and argued that the project actors played a central role in establishing, activating, and resolving them. This leads to a view of IOPs as a particular space for changing and negotiating temporal orientations that allows for new and shared practices to emerge. The relation between temporal tensions and practices lies in changing past-present-future orientations and calls for a kind of "boundary-spanning organizational mechanism" that does not center on the physical and spatial dimensions of organizing but instead zooms in on its temporal dimensions. In that respect, we relied on an analytical approach that addressed the duality of IOPs as both initiators and solutions of temporal-tension problems. The initiators of the SK program understood that the local SK projects would create temporal tensions among the actors who took part in the interorganizational collaboration. At the same time, the SK program and the local SK projects were organized to ensure that sufficient attention and resources were in place to cope with and resolve these tensions, and thus establish better, more operational collaborations among the interacting organizations.

As discussed in prior research on temporal differences (see, e.g., Ancona and Waller, 2007; Dille and Söderlund, 2011; Gersick, 1994; Reinecke and Ansari, 2015), there is a need for studies that go beyond simple descriptions of activitysynchronization problems to address the aspects of time and time-reckoning systems involved in complex crossorganizational collaboration. This implies a focus on the actual practices and situated activities among actors in IOPs in order to identify the various temporal tensions involved as well as the practices these actors utilize to address those tensions. This framing is in line with Orlikowski and Yates's (2002) idea of "temporal structuring" as a central element of project contexts. An examination of the multiplicity of temporalities also seems essential if we are to better understand how projects evolvehow they move from initiation to completion, how tensions change, and how practices address tensions while also leading to new tensions. However, the context of IOPs implies additional challenges associated with temporalities among the participating organizations. For these reasons, we asked: What temporal tensions are involved in an IOP? What practices do actors in these projects adopt to transform the temporal tensions into collaboration?

The theory suggested in this paper highlights specific temporal-boundary mechanisms and their management as focusing to a great extent on the temporal tensions involved in the projects covered in our research. We rely on a practicebased perspective (Feldman and Orlikowski, 2011; Nicolini, 2012) to analyze the nature and management of IOPs, thereby illuminating how temporal tensions are identified and resolved as part of the ongoing practices that project actors use to make sense of temporal differences and agree on ways to resolve them. The three practices that we identified encompass a range 
of activities that move a project toward the future goal of developing collaborative relationships across the supply chain. The tensions we identified were rooted in organizational routines and cultures, which were molded into each organization to different degrees. These routines and cultures that were primarily rooted in a past orientation, needed to be overcome in order to drive a project forward, taking on a more future orientation. However, this was more than a case of merely overruling one for the sake of the other. It was, in fact, a matter of negotiating competing temporalities (Reinecke and Ansari, 2015) throughout the course of the project. IOPs force participants to move through different temporal orientations that solve certain tensions emerging as the IOP moves along. At the first stages it primarily forces participants toward a more future oriented perspective as the motivation for changing practices are initiated by the memories of the past and the expectations for a better future (Schatzki, 2010). Creating an awareness of and negotiating time horizons is fundamentally set these future expectations to allow for new practices to emerge. As the IOP as such triggered a win-win mentality, seeking to solve the tensions arising from misaligned of timing norms among the participating organizations, the IOP forced participants to be focused on the present and finding solutions together with their partners. At later stages of the IOP, the main challenge seemed to be the tension between continuing past practices whilst implementing the new practices coming from the IOP into the more permanent organizational context. The permanent organizational context compared with the temporary IOP implied a stronger past orientation toward routinized practices that had proved successful in the past which made it difficult to engage in new alternative practices. The practice of hyping seems to make the practices oriented toward the past illegitimate by framing those as "the old unfruitful way" while hyping the successes of the new and future practice. This pressure was only possible to maintain through the foundation and success stories of the IOP.

IOPs are increasingly utilized to develop new systems, products, and processes. They offer the promise of diverse viewpoints and expertise, and they play a critical role in complex, interdependent problem solving (Lundin et al., 2015). However, temporal tensions constitute a fundamental problem for such projects, especially when those projects entail novel and complex problems and situations (Tsoukas, 2009). The three identified practices were used to overcome temporal tensions and, thereby, to co-create viable solutions that could ensure the implementation of the SK projects (see Table 2). The tensions arose from three kinds of temporalities: time horizon, pace and punctuality, and continuity. These different kinds of tensions were addressed through three boundary-spanning practices: framing, synchronizing, and hyping.

The framing practice had a strong future orientation, as it implied expanding or shrinking time horizons. This represented a way of playing with the time horizon for future collaboration. This future orientation entered into the core of power relations in the IOP, as the customer was often more likely than the supplier to end the collaboration. As such, it was the actor with the power to perform boundary work related to the future, which can be understood as a "projective capacity" of imagining alternative futures (Emirbayer and Mische, 1998). This implied playing with the boundaries of the future and defining the options for shorter-term or longer-term collaborations in order to motivate an IOP's progress.

The second practice involved negotiating and synchronizing pace and punctuality. This practice had a stronger orientation toward the present, as it led to discussions of urgent matters and expectations of current needs. This tension was even more

Table 2

Temporal tensions and boundary-spanning practices in interorganizational projects.

\begin{tabular}{|c|c|c|c|c|c|}
\hline Temporal tension & $\begin{array}{l}\text { Temporal boundary- } \\
\text { spanning practices }\end{array}$ & $\begin{array}{l}\text { Role of the interorganizational } \\
\text { project }\end{array}$ & $\begin{array}{l}\text { Dominant } \\
\text { time } \\
\text { conception }\end{array}$ & Intended impact & Unintended impact \\
\hline $\begin{array}{l}\text { Time-horizon tensions } \\
\text { Tensions arose from too } \\
\text { many or too few } \\
\text { projections of the future } \\
\text { of the } \\
\text { interorganizational } \\
\text { collaboration }\end{array}$ & $\begin{array}{l}\text { Framing } \\
\text { Setting the time horizon } \\
\text { for future collaboration }\end{array}$ & $\begin{array}{l}\text { Projecting a long-term } \\
\text { perspective for the collaboration. } \\
\text { Creating a better understanding of } \\
\text { a common future. }\end{array}$ & Future & $\begin{array}{l}\text { Suppliers harness and } \\
\text { comply with customers' } \\
\text { needs to improve the } \\
\text { collaboration }\end{array}$ & $\begin{array}{l}\text { For short-term orientations, } \\
\text { interorganizational trust may } \\
\text { be damaged and replaced with } \\
\text { a higher degree of } \\
\text { opportunism. } \\
\text { For overly long-term } \\
\text { orientations, the incentive to } \\
\text { invest is removed. }\end{array}$ \\
\hline $\begin{array}{l}\text { Pacing tensions } \\
\text { Tensions arose from } \\
\text { disparate timing norms } \\
\text { between organizations }\end{array}$ & $\begin{array}{l}\text { Synchronizing } \\
\text { Emphasizing or reducing } \\
\text { power to allow for a } \\
\text { shared temporal frame for } \\
\text { interorganizational } \\
\text { collaboration }\end{array}$ & $\begin{array}{l}\text { Imposing a win-win mentality } \\
\text { that seeks to minimize } \\
\text { organizational self-interest. } \\
\text { Solving day-to-day challenges to } \\
\text { avoid sub-optimization between } \\
\text { the two parties. }\end{array}$ & Present & $\begin{array}{l}\text { Enables the development } \\
\text { of shared timing norms } \\
\text { between organizations }\end{array}$ & $\begin{array}{l}\text { Shared timing norms require } \\
\text { change within the } \\
\text { organization. }\end{array}$ \\
\hline $\begin{array}{l}\text { Continuity tensions } \\
\text { Tensions arose from a } \\
\text { sense that past and } \\
\text { future tasks were } \\
\text { competing for attention }\end{array}$ & $\begin{array}{l}\text { Hyping } \\
\text { Pushing existing } \\
\text { organizational preferences } \\
\text { to focus on one or more } \\
\text { tasks at a time }\end{array}$ & $\begin{array}{l}\text { Implementing new practices } \\
\text { brought on by the SK program } \\
\text { involving potential savings and } \\
\text { benefit realization. Identifying } \\
\text { problems with past experience } \\
\text { and old routines. }\end{array}$ & Past & $\begin{array}{l}\text { Enables new practices to } \\
\text { be added to existing } \\
\text { practices }\end{array}$ & $\begin{array}{l}\text { The hyping of the change } \\
\text { could be out of sync between } \\
\text { the two organizations, leading } \\
\text { to the emergence of new pace } \\
\text { tensions. }\end{array}$ \\
\hline
\end{tabular}


pronounced in the interorganizational setting, where two sets of internalized timing norms met and tasks needed to be coordinated. This tension was negotiated in power relations in which a "time giver" defined the rhythm and dominated the "time taker" (Bluedorn, 2002). In order to resolve the tensions related to pace, boundary-spanning practices downplayed these

Table 3

Temporal boundary-spanning practices in interorganizational projects: a comparison.

\begin{tabular}{ll}
\hline Fescription & $\begin{array}{l}\text { Demarking the time horizon for future } \\
\text { collaboration }\end{array}$ \\
Tension & $\begin{array}{l}\text { Tensions arose from either too much or too little } \\
\text { projection of future collaboration }\end{array}$ \\
$\begin{array}{c}\text { Examples } \\
\text { of }\end{array}$ & $\begin{array}{l}\text { Framing by delimiting or expanding the time } \\
\text { horizon of the interorganizational collaboration }\end{array}$ \\
actions & by: \\
& \\
& - Stating a self-interest that delimits the future \\
& collaboration \\
& Suggesting a possible termination of the \\
& collaboration in the future \\
- & Bringing more competitors to the table \\
& Being part of an industry's future growth \\
& Offering incentives for longer-term \\
& collaboration
\end{tabular}

Illustrative "We are expecting growth of DKK 80 million in quotes revenue - an average growth rate of $30 \%$ per
year-and we need to build a foundation to year-and we need to build a foundation to handle this growth. Collaboration is essential in
this regard (and) ... when we look ahead, we all need to focus on our common customers-the automotive industry. We know that you need to earn money and you know that we need to make money, and we are dependent on each other." (CEO, Automotive, field notes)

Synchronizing

Hyping

Setting a new pace that fits both organizations' needs-redefining lead time in the production flow

Tensions arose from disparate timing norms between organizations

Synchronizing optimal timing norms by:

- Visualizing and discussing the current lead time

- Lowering the power distance to enable open and honest debate

- Challenging status quo timing norms and discussing optimal solutions

- Going beyond "the front stage" of standardized glorious sales speeches to a deeper engagement that enhances an understand the other party's timing norms and needs

"Great! It can be done, but it is not very optimal for you, is it?" (CEO, Automotive, field notes) "You need to get behind the key account managers because they have a completely different agenda. The projects in the SK program that fail are those in which the suppliers shut us off through the sales manager and we never get behind the scenes." (Project Member, Food Gamma, field notes)

"Now we invite them to the same table (to find "It helps if you have people who have worked for solutions), and we tell them the same story so your company in the supplier firm or vice versa. that nobody gets more information. As such, no It makes it much easier to discuss whether we are one has a competitive advantage in this regard. (Strategic Sourcing Manager, Food Delta) The best part is that the tender starts in a week, so possibilities for optimizing." (Procurement we will see what happens. "(Project Manager, Manager, Food Gamma, field notes)

Energy, field notes)

"One size fits all" is not good, but we need to "We compete in terms of our collaborators 1000 know that the supplier understands the urgency times per day (short-term collaborations on (understanding the client's tempi for different projects), so we are more like children from products), such that one product is more urgent composite families. ... What was interesting was than another. We also need a mitigation plan." to take part in the company 'dating' and discuss (Consultant) problems that can be solved because there is some money oozing out of the system. ... It was "It is amazing (that people do not agree on time also interesting to meet without a commercial facts).... We need to agree that we might not be intent." (Project Owner, Construction Alpha)

fully aligned on every feature. However, if it is a critical part ... then we need to find the data on it.

Interior Design Beta held a meeting with several ... You can ask if it is ... one or five hours. Then "I have a plan! As soon as the stock is tidied up, suppliers. The company presented the SK you ask if we can agree on the time span. Just to we will celebrate with coffee and cake in the area program and explained that although the startup enable a discussion... can we agree that we will where the goods used to be in the stock room." phase had been difficult, the program had been have something at some point between one hour (Procurement Manager, Food Gamma, field very successful after trust was established. In this and five hours? ... Then, how often is it one note) meeting, the CEO stated that "We are very loyal hour? Can we agree that $60 \%$ take one hour and and we will only initiate collaboration with a the rest take five hours or something in between? client that we trust, not someone who will Can we then agree that we have a weighted bargain for a better deal on the corner the next average that is closer to one hour than five day." (CEO, Interior Design Beta, field notes) hours?" (Consultant)
Creating a sense of urgency and importance around the project by turning to the "pain points" of the past

Tensions arose from a sense that tasks from the past and future compete for attention Hyping the interorganizational project by returning to the pain points of past collaborations:

- Reminding people of past frustrations

- Proving practices of the past to be financially unsustainable

- Celebrating new solutions by highlighting the changes made and reminding people of improvements on past pain points

- Setting up regular meetings

"For the past eight years, we have been running strategic purchasing using benchmarking and quantity pooling $\ldots$ but we have harvested the same field a few too many times. When you do that, every company makes less profit every time. ... Now we are entering a new phase in which we enter into a partnership in order to create more value and then split the profit equally." (Procurement Manager, Service)

"Whether you enter a company with a political intent or one that is merely business oriented matters, as you start the conversation in different places. ... It is important to be aware of what creates value for you." (DI Project Manager)

"You need to make sure that the rewards from the SK initiative rain down, so that the people who make the effort get the benefits." (Procurement Manager, Food Alpha)

"Actually, we worked on improving our internal processes, but I really believe that the key is to present some concrete results. (Procurement Manager, Food, Gamma)

We also worked on the soft parts of the processes, but hard results are just as important." (Process Excellence Director, Transport Beta)

\author{
?
}


power relations and allowed for negotiations that aligned the disparate timing norms.

The third practice entailed hyping change. This practice predominantly had a past orientation, as experience had demonstrated that certain tasks were central to the company's survival. Hence, the tasks of the past were critical for vague projections of an even better return on investment after the implementation of new practices. In this regard, people routinely drew on shared temporal structures (Orlikowski and Yates, 2002), which tended to reenact the past when they were used to organize current activities and tasks. Overall, hyping practices were essential in efforts to add more tasks (multichronicity) or to change tasks in attempts to refine old practices.

Even though our empirical account treats the tensions and practices as distinct, we wish to emphasize that the tensions in IOPs are interlinked. Tension I, which is related to time horizons, is the prerequisite for incentives to initiate an IOP. Tension II, which is linked to pacing, is primarily a prerequisite for the quality and optimization of interorganizational collaboration. Tension III, which is associated with continuity, is primarily centered on the implementation of the necessary changes. Hence, it is a result of effectuating a transition from the IOP to the permanent organization.

The practices are also interdependent, as the framing practices motivate suppliers to engage in solving other tensions. However, in our study, new tensions emerged from these efforts, especially tensions related to delimiting time. These new tensions sent mixed signals to suppliers and created distrust in interorganizational relationships. Synchronization is essential for coming up with shared timing norms to ensure the IOP's continuity. Hyping is used to finalize the intended transition. However, this creates new tensions between suppliers and buyers because hyping is not always practiced in the suppliers' and customers' organizations, leaving them out of sync in terms of the timing norms, thereby giving rise to pace tensions.

As such, the practices helped project actors overcome a number of challenges associated with idiosyncratic temporalities. By speaking openly and confronting each organization's molded temporal practices, the IOP was able to express doubts about overcoming temporal tensions in the project. Thus, our descriptions of the practices extends the literature on temporal tensions across organizations. More specifically, we show how temporal boundary spanning can be used to resolve the temporal tensions evident across organizations participating in an IOP. Table 3 provides an overview of the three practices and how they relate to temporal tensions.

\subsection{Theoretical implications}

Time is at the core of project management and ubiquitous in the project management literature. This has resulted in a knowledge domain that subscribes to the quantitative time and clock-based structures that shape organizations' temporal practices (Orlikowski and Yates, 2002) with, for instance, a strong focus on the significance of deadlines (Lindkvist et al., 1998) and schedules (Yakura, 2002). This address of organizational temporality has paved the way for an understanding of synchronization and another main concern of project managers: estimating the time needed to complete a particular activity and linking activities to each other. However, this "clock-time hegemony" tends to "eclipse alternative conceptions such as qualitative time" (Reinecke and Ansari, 2015: 619). Moreover, it fails to capture differences in perceptions of time across organizations, cultures, and communities (Barkema et al., 2002). This paper adopts a different perspective on temporality in projects by zooming in on temporal tensions across participants in an IOP. By focusing on this kind of project, we are able to contribute to the emerging literature on IOPs as a particular organizational form (see, for instance, Sydow and Braun, 2017), as we offer a practice-based approach that highlights the significance of temporal tensions and the ways in which management seeks to resolve those tensions.

The theoretical implications are the following. First, we offer a novel perspective on IOPs that highlights their role as initiators of both boundary-spanning needs and solutions to boundary-spanning problems. We introduce the central practices performed in IOPs as a form of temporal boundary spanning. The main characteristics of a project relate to time (future orientation), tasks (present), team (boundary spanners), and transitions (past orientations) (see Lundin and Söderholm, 1995), and we show how these characteristics are aligned with the temporal dimensions of past, present, and future. This also leads to a temporal perspective on the management of a project as important for resolving the various temporal tensions involved in that project.

Our identification of three central practices-framing, synchronizing, and hyping - also contributes to the literature on IOPs and provides a more nuanced understanding of the reality of project management in this context. In this regard, we help answer the essential question of why these projects exist and the role management plays in these projects (Söderlund, 2004, 2011). The temporality issues run as a central theme in our framework, which seems fitting given the focus on timerelated concepts, such as interdependencies, synchronization, milestones, and deadlines, that are widespread in the projectmanagement literature and related research on temporary organizations (Bakker, 2010; Lundin and Söderholm, 1995).

\subsection{Practical implications}

It seems particularly important for managers to develop a better temporal understanding of IOPs and to acknowledge the fact that IOPs are sometimes implemented to function as timereckoning systems (Clark, 1985) designed to align the temporal understanding of the organizations involved. This insight goes beyond merely addressing IOPs as mechanisms for activity coordination and synchronization. Such a temporal understanding would also make project actors more aware of the time regularities in each of the involved organizations. Therefore, identifying the nature and significance of temporal tensions seems to be an essential part of project management and organization in these settings. 
The use of a repertoire of practices, including framing, synchronizing, and hyping, is certainly a central task for management in IOPs. Moreover, developing a capability to understand this breadth of temporal practices and how they can best be combined to achieve an overall temporal understanding is critical for all involved organizations as well as the people responsible for these projects.

\subsection{Limitations}

In this paper we studied IOPs in several different industries. It should be pointed out that we have not within the scope of this paper addressed these contextual differences fully. Hence this paper runs the risk of offering conclusions that are only applicable to the selected IOPs that were part of this specific program within this specific and somewhat narrow empirical setting. We have compensated for this limitation by explicitly framing our discussion and analysis within well-established theory and current literature on IOPs and temporality. Nevertheless, we would like to underline that our model and the three identified practices are tentative, and that the model requires further empirical research and validation in other empirical contexts. Furthermore, our findings open up for a need for further research on the role of management of pastpresent and future in and between projects and more permanent organizations and institutions. One of the main curiosities that this paper raise in this regard is a more nuanced understanding of the processes and relations between temporal tensions and how they are enacted and solved at different stages during the life of an IOP.

\section{Conclusion}

This paper offers a novel perspective on the nature and challenges of IOPs. We view these projects as mechanisms that create and resolve temporal tensions among organizations, and thus consider temporal tensions as an integral part of the nature and dynamics of IOPs. The introduction of the notion of temporal boundary spanning gives rise to a new way of addressing and understanding the management of such projects -we can examine the temporal tensions inherent in them as well as the three primary temporal boundary-spanning practices that project actors utilize to resolve those tensions and ensure project progression.

\section{Acknowledgements}

We thank the Special Issue Editors and the anonymous reviewers for their helpful suggestions and guidance in improving the paper, as well as sub-theme participants at EGOS 2017 for their comments.

We gratefully acknowledge the funding and support from The Confederation of Danish Industry as well the participants from the program Stram Kæden for their insights and time during our research. Also, we thank Brightline for funding during the finalizing of the paper.

\section{Appendix A. List of interviews}

\begin{tabular}{|c|c|c|c|c|c|}
\hline & Position & Interview type & Company type & Date & $\begin{array}{l}\text { Interview } \\
\text { duration }\end{array}$ \\
\hline 1 & Management Consultants & $\begin{array}{l}\text { Group } \\
\text { (2 participants) }\end{array}$ & Consulting & 27.06.2016 & $61 \mathrm{~min}$ \\
\hline 2 & Management Consultant & Single & Consulting & 20.9.2016 & $134 \mathrm{~min}$ \\
\hline 3 & $\begin{array}{l}\text { Procurement Manager, Controller, Management Assistant, Factory and } \\
\text { Logistics Manager, } \\
\text { Planning Assistant }\end{array}$ & Group (5) & Food Gamma & 17.11.2016 & $77 \mathrm{~min}$ \\
\hline 4 & Factory and Logistics Manager & Single & Food Gamma & 17.11.2016 & $54 \min$ \\
\hline 5 & Management Assistant & Single & Food Gamma & 17.11.2016 & $81 \mathrm{~min}$ \\
\hline 6 & Procurement Manager & & Food Gamma & 17.11.2016 & $76 \min$ \\
\hline 7 & COO, Chief Clerk, Sourcing Manager & Group (3) & Interior Design Gamma & 26.10 .2016 & $84 \mathrm{~min}$ \\
\hline 8 & $\begin{array}{l}\text { Spare-part Stock Supervisor, } \\
\text { Project Manager, Warehouse Supervisor, Supply Chain Manager }\end{array}$ & Group (4) & Food Delta & 15.11.2016 & $84 \min$ \\
\hline 9 & Global Report Analyst, Strategic Buyer & Group (2) & Food Delta & 20.10 .2016 & $119 \min$ \\
\hline 10 & Global Purchasing Manager & Single & Food Delta & 18.10.2016 & $44 \mathrm{~min}$ \\
\hline 11 & Purchasing Manager & Single & Food Delta & 16.10 .2016 & $72 \min$ \\
\hline 12 & Supply Chain Assistant & Single & Food Delta & 16.10.2016 & $44 \mathrm{~min}$ \\
\hline 13 & Global SAP Report Analyst Support, Strategic Buyer & Group (2) & Food Delta & 14.12.2016 & $122 \mathrm{~min}$ \\
\hline 14 & Project Manager & Single & Transport Alpha & 14.12.2016 & $56 \mathrm{~min}$ \\
\hline 15 & Project Manager & Single & Transport Alpha & 14.12.2016 & $44 \mathrm{~min}$ \\
\hline 16 & CEO & Single & Technical Systems & 27.10.2016 & $92 \mathrm{~min}$ \\
\hline
\end{tabular}


(continued)

\begin{tabular}{|c|c|c|c|c|c|}
\hline & Position & Interview type & Company type & Date & $\begin{array}{l}\text { Interview } \\
\text { duration }\end{array}$ \\
\hline 17 & Purchasing Director & Single & Service & 13.12 .2016 & $71 \mathrm{~min}$ \\
\hline 18 & Senior Strategic Purchaser & Single & Service & 13.12 .2016 & $62 \mathrm{~min}$ \\
\hline 20 & Vice President, Supply Chain and Procurement & Single & High Tech & 23.11.2016 & $80 \mathrm{~min}$ \\
\hline 21 & Senior Manager Procurement & Single & Food Alpha & 11.10.2016 & $163 \mathrm{~min}$ \\
\hline 22 & Project Coordinator & Single & Food Alpha & 11.10 .2016 & $55 \mathrm{~min}$ \\
\hline 25 & Supply Chain Consultant & Single & Consultant & 08.01 .2017 & $75 \mathrm{~min}$ \\
\hline 26 & Senior Consultant & Single & Confederation of Danish Industry & 21.12.2016 & $45 \min$ \\
\hline 27 & Supply Chain Consultant & Single & Consultant & 06.01 .2017 & $76 \min$ \\
\hline 28 & Environment, Business Development Manager & Single & Energy & 18.01.2017 & $55 \mathrm{~min}$ \\
\hline 29 & Purchase and Process Analyst & Single & Energy & 18.01.2017 & $113 \mathrm{~min}$ \\
\hline 30 & Section Manager & Single & Energy & 18.01.2017 & $58 \mathrm{~min}$ \\
\hline 35 & Sourcing Manager, R\&D Engineering & Single & Interior Design Alpha & 24.01.2017 & $47 \mathrm{~min}$ \\
\hline 36 & Purchaser & Single & Interior Design Alpha & 24.01.2017 & $51 \mathrm{~min}$ \\
\hline 37 & Purchaser & Single & Interior Design Alpha & 24.01.2017 & $70 \mathrm{~min}$ \\
\hline 38 & Purchaser & Single & Interior Design Alpha & 24.01 .2017 & $56 \min$ \\
\hline 39 & Commissioning Manager & Single & Transport Beta & 14.12.2016 & $58 \mathrm{~min}$ \\
\hline 40 & Process Excellence Director & Single & Transport Beta & 11.01.2017 & $51 \mathrm{~min}$ \\
\hline 41 & Owner & Single & Transport Beta & 18.04 .2017 & $64 \min$ \\
\hline 42 & Director, Owner & Single & Transport Beta & 18.04.2017 & $78 \mathrm{~min}$ \\
\hline 43 & IT Manager, Operations Manager & Group (2) & Transport Beta & 18.04.2017 & $76 \min$ \\
\hline 44 & $\mathrm{CEO}$ & Single & Automotive & 13.01.2017 & $123 \mathrm{~min}$ \\
\hline 45 & Strategic Purchasing Manager, two Project Managers & Group (3) & Construction Alpha & 31.01 .2017 & $108 \mathrm{~min}$ \\
\hline 46 & Steering Group Meeting & Group (4) & Federation of Danish Industry & 17.08.2017 & $55 \mathrm{~min}$ \\
\hline 47 & Steering Group Meeting & Group (5) & Federation of Danish Industry & 05.01 .2017 & $72 \mathrm{~min}$ \\
\hline
\end{tabular}

\section{References}

Alioua, H., Simon, F., 2017. Managing time pacing in organizations transitioning to a project-based mode. Int. J. Proj. Manag. 35, 1427-1443.

Alvesson, M., Sköldberg, K., 2011. Reflexive Methodology: New Vistas for Qualitative Research. Third edition. SAGE Publishing, London.

Ancona, D., Waller, M., 2007. The Dance of Entrainment: Temporally Navigating across Multiple Pacers. Workplace Temporalities. Res. Sociol. Work. 17, 115-146.

Bakker, R., 2010. Taking Stock of Temporary Organizational Forms: A Systematic Review and Research agenda. Int. J. Manag. Rev. 12, 466-486.

Barkema, H., Baum, J., Mannix, E., 2002. Management challenges in a new time. Acad. Manag. J. 45 (5), 916-930.

Bechky, B.A., 2003. Sharing meaning across occupational communities: The transformation of understanding on a production floor. Organ. Sci. 14 (3), 312-330.

Bluedorn, A.C., 2002. The human organization of time: Temporal realities and experience. Stanford University Press, Stanford, CA.

Bluedorn, A., Waller, M., 2006. The stewardship of the temporal commons. Research in Organizational Behavior: An Annual Series of Analytical Essays and Critical Reviews. vol. 27, pp. 355-396.

Casey, M., 2008. Partnership - success factors of interorganizational relationships. J. Nurs. Manag. 16, 72-83.

Clark, P., 1985. A Review of Theories of Time and Structure for Organizational Sociology. In: Bacharach, S.B., Mitchel, S.M. (Eds.), Research in the Sociology of Organizations. 4. JAI Press, Greenwich, CT, pp. 125-176.
Dahlgren, J., Söderlund, J., 2001. Managing inter-firm projects: On pacing and matching hierarchies. Int. Bus. Rev. 10, 305-322.

Dille, T., Söderlund, J., 2011. Managing inter-institutional projects: The significance of isochronism, timing norms and temporal misfits. Int. J. Proj. Manag. 29, 480-490.

Dille, T., Söderlund, J., 2013. Managing temporal misfits in institutional environments. A study of critical incidents in a complex public project. Int. J. Manag. Proj. Bus. 6 (3), 552-575.

Dille, T., Söderlund, J., Clegg, S., 2018. Temporal conditioning and the dynamics of inter-institutional projects. Int. J. Proj. Manag. 36, 673-686.

Ebers, M., 1997. Explaining inter-organizational network formation. In: Ebers, M. (Ed.), The formation of interorganizational networks. Oxford University Press, Oxford

Emirbayer, M., Mische, A., 1998. What is agency? Am. J. Sociol. 103 (4), 962-1023.

Feldman, M., Orlikowski, W., 2011. Theorizing Practice and Practicing Theory. Organ. Sci. 22 (5), 1240-1253.

Flyvbjerg, B., 2017. Introduction: The iron law of megaproject management. The Oxford handbook of megaproject management. Oxford University Press, Oxford, UK, pp. 1-18.

Gersick, C.J.G., 1994. Pacing Strategic Change: The Case of a New Venture. Acad. Manag. J. 37 (1), 9-45.

Gieryn, T.F., 1983. Boundary-work and the demarcation of science from nonscience: strains and interests in professional ideologies of scientists. Am. Sociol. Rev. 48 (6), 781-795. 
Gieryn, T.F., 1999. Cultural boundaries of science: credibility on the line. University of Chicago Press, Chicago, Ill.

Grabher, G., 2004. Temporary Architectures of Learning: Knowledge Governance in Project Ecologies. Organ. Stud. 25 (9), 1491-1514.

Granqvist, N., Gustafsson, R., 2016. Temporal Institutional work. Acad. Manag. J. 59 (3), 1009-1035.

Hobday, M., 2000. The project-based organization: An ideal form for managing complex products and systems. Research Policy. 29, pp. 871-893.

Hsu, Hannan, Kocak, 2009. Multiple Category Memberships in Markets: An Integrative Theory and Two Empirical Tests. Am. Sociol. Rev. 74 (1), 150-169.

Jones, C., Lichtenstein, B., 2007. Temporary Interorganizational Projects: How Temporal and Social Embeddedness Enhance Coordination and Manage Uncertainty. In: Cropper, S., Ebers, M., Ring, P.S., Huxham, C. (Eds.), Handbook of Interorganizational Relations. Oxford University Press, London, pp. 231-255.

Kellogg, K.V.C., Orlikowski, W.J., Yates, J.-O., 2006. Life in the Trading Zone: Structuring Coordination Across. Boundaries in Postbureaucratic Organizations. Organ. Sci. 17 (1), 22-44

Kenis, P., Janowicz-Panjaitan, M., Cambré, B., 2009. Temporary organizations: Prevalence, logic and effectiveness. Cheltenham: Edward Elgar.

Klag, M., Langley, A., 2013. Approaching the Conceptual Leap in Qualitative Research. Int. J. Manag. Rev. 15, 149-166.

Klarner, P., Raisch, S., 2013. Move to the beat: Rhythms of change and firm performance. Acad. Manag. J. 56, 160-184.

Kreiner, G.E., Hollensbe, E.C., Sheep, M.L., 2009. Balancing borders and bridges: Negotiating the workhome interface via boundary work tactics. Acad. Manag. J. 52 (4), 704-730.

Lenfle, S., Söderlund, J., 2018. Large-scale innovative projects as temporary trading zones: Toward an interlanguage theory. Organization Studies, online first, pp. 1-27.

Ligthart, R., Oerlemans, L. and Noorderhaven, N. (2016). In the Shadows of Time: A Case Study of Flexibility Behaviors in an Interorganizational Project. Organ. Stud., 37(12), 1721-1743.

Lindkvist, L., Söderlund, J., Tell, F., 1998. Managing product development projects: on the significance of fountains and deadlines. Organ. Stud. 19 (6), 931-951.

Lundin, R., Söderholm, A., 1995. A theory of the temporary organization. Scand. J. Manag. 11 (4), 437-455.

Lundin, R.A., Arvidsson, N., Brady, T., Ekstedt, E., Midler, C., Sydow, J., 2015. Managing and working in project society. Institutional challenges and temporary organizations. Cambridge University Press, UK.

Manning, S., 2017. The rise of project network organizations: Building core teams and flexible partner pools for interorganizational projects. Res. Policy $46,1399-1415$.

Maurer, I., 2010. How to build trust in inter-organizational projects: The impact of project staffing and project rewards on the formation of trust, knowledge acquisition and product innovation. Int. J. Proj. Manag. 28, 629-637

Mors, 2010. Innovation in a global consulting firm. When the problem is too much diversity. Strateg. Manag. J. 31 (8), 841-872.

Nicolini, D., 2012. Practice Theory, Work, and Organization: An Introduction. University Press, Oxford.

Oliveira, N., Lumineau, F., 2017. How Coordination Trajectories Influence the Performance of Interorganizational Project Networks. Organ. Sci. 28 (6), $1029-1060$.

O'Mahony, S., Bechky, B., 2008. Boundary Organizations: Enabling Collaboration among Unexpected Allies. Adm. Sci. Q. 53, 422-459.
Orlikowski, W., Yates, J., 2002. It's About Time: Temporal Structuring in Organizations. Organ. Sci. 13 (6), 684-700.

Reinecke, J., Ansari, S., 2015. When times collide: temporal brokerage at the intersection of markets and developments. Acad. Manag. J. 58 (2), $618-648$

Schatzki, T.R., 2010. The timespace of human activity: On performance, society, and history as indeterminate teleological events. Lexington, Lanham, MD.

Schatzki, T.R., Knorr, Cetina.K., von Savigny, E., 2001. The Practice Turn in Contemporary Theory. Routledge, London, New York.

Scott, R., Levitt, R.E., Orr, R.J., 2011. Global Projects: Institutional and Political Challenges. Cambridge University Press, Cambridge, UK.

Selin, C., 2006. Time matters: Temporal harmony and dissonance in nanotechnology networks. Time Soc. 15 (1), 121-139.

Söderlund, J., 2004. Building theories of project management: past research, questions for the future. Int. J. Proj. Manag. 22, 183-191.

Söderlund, J., 2011. Theoretical foundations of project management: Suggestions for a pluralistic understanding. In: Morris, P., Pinto, J., Söderlund, J. (Eds.), Oxford Handbook of Project Management. Oxford University Press, Oxford, pp. 37-64.

Souitaris, V., Maestro, B.M., 2010. Polychronicity in top management teams: The impact on strategic decision processes and performance of new technology ventures. Strateg. Manag. J. 31, 652-678.

Star, S.L., 2010. This is not a boundary object: Reflections on the origin of a concept. Sci. Technol. Hum. Values 35 (5), 601-617.

Stock, R.M., 2006. Interorganizational teams as boundary spanners between supplier and customer companies. J. Acad. Mark. Sci. 34 (4), 588-599.

Sydow, J., Braun, T., 2017. Projects as temporary organizations: An agenda for further theorizing the interorganizational dimension. Int. J. Proj. Manag. 36 (1), 4-11.

Thompson, J., 1967. Organizations in action. Social sciences bases on administrative theory. McGraw-Hill Book.

Tsoukas, H., 2009. A dialogical approach to the creation of new knowledge in organizations. Organ. Sci. 20 (6), 941-957.

Van de Ven, A.H., Delbecq, A.L., Koenig, J.R.R., 1976. Determinants of coordination modes within organizations. Am. Sociol. Rev. 41 (2), 322-338.

Van Vijk, R., Jansen, J. and Lyles, M. (2008). Inter- and intra-organizational knowledge transfer: A meta -analytic review and assessment of its antecedents and consequences, J. Manag. Stud., 45(4), 0022-2380.

Werr, A., Blomberg, J., Löwstedt, J., 2009. Gaining external knowledge boundaries in managers' knowledge relations. J. Knowl. Manag. 13 (6), 448-463.

White, H., 1992. Identity and Control. Princeton University Press, Princeton, NJ.

Yakura, E.K., 2002. Charting time: Timelines as temporal boundary objects. Acad. Manag. J. 45 (5), 956-970.

Zerubavel, E., 1981. Hidden Rhythms. University of Chicago Press, Chicago.

Zuckerman, E.W., 2016. Optimal distinctiveness revisited: an integrative framework for understanding the balance between differentiation and conformity in individual and organizational identities. Oxford, UK. In: Pratt, M.G., Schultz, M., Ashforth, B.E., Ravasi, D. (Eds.), Oxford Handbook of Organizational Identity. 